\title{
A OCUPAÇÃO E OS ESPAÇOS DE DIMENSÕES DE SOCIABILIDADE DO INTERIOR PAULISTA NA LÓGICA DA “VIA PRUSSIANO-COLONIAL" DE FORMAÇÃO CAPITALISTA

\section{DONZELLI, Cledivaldo Aparecido ${ }^{1}$}

https://orcid.org/0000-0002-0100-4164

RESUMO: $O$ artigo versa sobre as tipologias do capitalismo inseridas em condições históricas diversas, fundamentais para a compreensão da mudança desse sistema e da formação da burguesia brasileira. Apresenta a dinâmica própria da constituição da mesma dentro do processo de emancipação e constituição da nação brasileira no viés conservador que dista do processo revolucionário clássico verificado na França e Inglaterra. A trajetória caracterizada por conciliações entre as elites brasileiras levada a cabo principalmente pela burguesia agrária torna emblemático o processo de ocupação do território paulista com seus específicos contornos de constituição de bairros rurais, vilas e cidades. $O$ artigo demonstra as tardias instituições responsáveis pelas tentativas de estímulo aos usos da civilidade, homogeneização identitária e da formação de narrativas sobre a epopeia histórica da destruição do atraso no sertão bravio paulista.

PALAVRAS-CHAVE: Capitalismo; Povoamento; Interior paulista.
ABSTRACT: The article deals with the typologies of capitalism inserted in different historical conditions, fundamental to the understanding of the change of this system and the formation of the Brazilian bourgeoisie. It presents the dynamics proper to its constitution within the process of emancipation and constitution of the Brazilian nation in the conservative bias that is far from the classic revolutionary process verified in France and England. The trajectory characterized by conciliation between the Brazilian elites carried out mainly by the agrarian bourgeoisie makes the process of occupation of São Paulo territory emblematic with its specific contours of constitution of rural neighborhoods, towns and cities. The article demonstrates the late institutions responsible for attempts to stimulate the uses of civility, homogenization of identity and the formation of narratives about the historical epic of the destruction of backwardness in the backwoods of São Paulo.

KEYWORDS: Capitalism; Settlement; São Paulo countryside.

1 Doutorando em Ciências Sociais pela Universidade Estadual Paulista Júlio de Mesquita Filho de Marília - SP, mestre em História pela Universidade Estadual Paulista Júlio de Mesquita Filho de Assis - SP, especialista em História do Brasil pela PUC de Belo Horizonte - MG e graduado em História pela Fundação Educacional de Penápolis. Atualmente é professor da Fundação Educacional de Penápolis. E-mail: cledivaldoaparecidodonzelli@gmail.com 


\section{INTRODUÇÃO}

O presente artigo propõe reflexões acerca do entendimento de que o capitalismo apresentou dinâmicas próprias de implementações a partir das condições históricas singulares de cada localidade. Mostra as diferentes nuances, dentre elas, aquela encontrada empiricamente na Inglaterra e França, reconhecida na consubstanciação de um modelo, onde sua trajetória foi pautada no desenvolvimento do comércio, no renascimento e transformações das cidades e das notórias revoluções tecnológicas proporcionadoras de uma brutal mudança das relações sociais de produção retirando milhões de pessoas nas condições de artesãos e camponeses e os inserindo dentro de uma lógica de civilidade balizada pelos ditames dos novos valores e costumes de uma classe social protagonista desse processo, e, portanto, revolucionária, a burguesia.

O artigo demonstra também, que essa denominada via reconhecida como clássica não se dá da mesma forma em outras partes do planeta, em função das condições históricas próprias da constituição de uma classe burguesa que minimiza e torna mais lenta a transição para o capitalismo, por ser uma classe social que adota os componentes de produção próprios do capitalismo na produtividade no campo, devido sua gênese no contexto feudal específico. Isso freará as transformações e trará uma conformação de poder onde não se verificam rupturas e sim conciliações responsáveis por um distanciamento da via clássica, principalmente no campo político, onde se tolera e eventualmente se aceita a autocracia para a segurança das elites empreendedoras desse modelo de sociedade. Isso se dará em grande medida na Alemanha e servirá para a compreensão das formulações de papeis e funções do Estado garantidor ou não das condições de existência a de sua população. Um Estado bem feitor e interventor e que equilibraria as forças em tensão visando um perene processo de manutenção do establishment das elites oriundas dessa conciliação.

As reflexões remeteram também para as condições próprias verificadas na América, onde o colonialismo escravista canalizou através do mercantilismo insumos para o acúmulo primitivo de capitais para as metrópoles europeias e que, no momento dos processos emancipacionistas das nações americanas, as condições foram dadas para a avidez das nações europeias pela extensão dos seus tentáculos visando matérias-primas, mercado consumidor e mão de obra em abundância.

As elites produtivas locais assentadas no modo de produção escravista, buscavam sintonizar-se com a modernidade dos processos produtivos capitalistas e assim introduziram de forma a não ocorrer rupturas que pudessem colocar em risco e ampliar espaços de participações de uma incipiente burguesia urbana e industrial e assim desmontar de vez 
o modelo antigo de produção agrária exportadora. Com isso, se verificou no território americano, com suas conformações variadas, outra via com especificidade própria que atrasou sobremaneira a introdução da civilidade clássica europeia e propiciou um modelo político com contornos de uma autocracia, que fragilizou a tão decantada cidadania e Estado de direitos, a "via prussiano- colonial".

Isto posto, o artigo pretende também demonstrar que a inserção do processo de povoamento e constituição de bairros rurais, vilas, vilarejos e cidades no território paulista a partir do século XIX, se deu nas condições próprias e inseridas na via "prussiano colonial", levada a cabo por uma burguesia rural financiada por um Estado e nação que implementava um espectro político de conformação e conciliação entre as elites formadas por produtores rurais, profissionais liberais, comerciantes brasileiros e estrangeiros e uma incipiente elite industrial.

O artigo, portanto, versará sobre a emblemática expansão de ocupação de espaço no interior do Estado de São Paulo iniciado a partir de finais do século XIX carregado de discursos reverberados da influência inglesa pautado no pioneirismo e nos ditames do progresso. Pretende-se, com isso, apresentar os componentes de uma modernização presentes na ocupação desse território, tais como o cultivo em larga escala do café, linha férrea e introdução de algumas indústrias com capitais nacionais e estrangeiros. Com isso, se constata uma configuração própria da paisagem urbana paulista com estética arquitetônica e legislações que acenavam para uma tentativa de modernidade mimetizada em cidades centenárias europeias ou até mesmo em capitais como São Paulo e Rio de janeiro. Além disso, criam se também espaços de sociabilidade nos meios urbanos específicos de uma região que se expandia pelo estímulo de atração de imigrantes, que deu contornos a uma híbrida população que vislumbrava a partir de negociações de identidades, uma homogenia narrativa de valores e papeis no processo pioneiro e na epopeia de modernização dos sertões paulistas. Doravante, erigiram clubes de serviço, clubes sociais, associações e museus para a veiculação dos usos de uma civilidade e de práticas aceitas que distinguiam e uniam grupos de identificações de classe, nacionalidade e de raça.

A tessitura do artigo se deu através da consulta bibliográfica que permeou reflexões acerca de conceitos e ideias fundamentais para a inteligibilidade da temática. Os conceitos e debates sobre processo civilizador, espaços de sociabilidade, grupos, espaços de memória e capitalismo foram fundamentais para o embasamento às respostas da hipótese que é a relação do desenvolvimento do capitalismo brasileiro pela "via prussiano-colonial" com a tardia inserção de práticas e representações em torno da civilidade no processo de 
povoamento do interior paulista.

\section{AESPECIFICIDADE DA CONSTITUIÇÃO DA BURGUESIAE DAFORMAÇÃO DO CAPITALISMO BRASILEIRO}

A constituição da paisagem urbana no Brasil tem uma gênese em comum com a de vários países latino-americanos, mas também possui especificidade por conta da engenharia de formação do capitalismo que se difere do denominado modelo clássico observado na Europa e mesmo da trajetória da formação do capitalismo nas Américas. Para isso, é salutar apresentar as trajetórias históricas díspares da Europa e América para a inteligibilidade das especificidades da paisagem urbana, principalmente brasileira, que será desenvolvida no próximo item.

Em todo território americano se verificou uma evolução do capitalismo onde empiricamente foi possível identificar as suas condições históricas específicas, pois o modelo clássico percebido na Europa, a partir das condições históricas próprias de constituição da burguesia, enquanto classe social revolucionária na França e Inglaterra serve para compreender o padrão estrutural do capitalismo norteador paradigmático de um modelo para outras regiões fora da Europa.

As características do capitalismo - mais-valia, capital, lucro e salário - permeiam os demais, mas os ritmos e dinâmicas são díspares e também tardios. No caso das Américas, diferentemente da Europa experienciou-se o colonialismo escravocrata, canalizador de um acúmulo primitivo de capital pelas metrópoles europeias, levado a cabo pelo mercantilismo.

O colonialismo escravocrata foi incompatível com a dinâmica histórica da formação de uma burguesia urbana, comercial e industrial europeia, que desde o modo de produção feudal acumula um poder econômico ao ponto de exigir também o poder político para a implementação de escopo governamental capaz de garantir a sua consolidação e expansão. Ela se tornou revolucionária por colocar em xeque o status quo da nobreza feudal e assim instituir um novo establishment do qual permeia um processo civilizador (ELIAS, 1994), agora sobre a égide de relações capitalistas de produção e vivência em espaços de sociabilidade modernos nos ambientes urbanos e industriais.

Nas Américas, contudo, a economia pautada nas relações de trabalho escravo e a existência de colonos cuja prática econômica estava na produção de gêneros agrícolas para servir os ditames dos mercados internacionais implementados pelas suas metrópoles, freou seu surgimento, como deu contornos bem diferentes à uma classes social que viria a ser a burguesia americana com suas facetas agrária, financista, comercial e industrial típicas 
desse continente.

Nas sociedades capitalistas clássicas as instituições emergem para cimentar os valores modernos no campo da economia, sociedade e política e assim inventam outra tradição de forma a prospectar um futuro prometido graças às revoluções oriundas das fontes de energia, meios de transportes e nas maquinarias. O progresso se apresenta alvissareiro e o desencantamento do mundo obscuro do feudalismo agrário e práticas sociais rurais estavam formulando novas identidades que passavam pela noção de nação e de classes sociais, até mesmo de raça. Momento de exacerbação das crenças nas ciências e desconfianças nas explicações transcendentais das religiões.

Para essas reflexões, é essencial apresentar a caracterização da denominada via clássica do capitalismo europeu realizada por Mazzeo (1989) dentro de um processo específico da história social e econômica da Europa:

Podemos, assim, notar que no bojo do processo de ascensão revolucionária da burguesia, surge o espaço histórico para a ampla participação e organização das massas populares, quer no processo da guerra civil inglesa, quer no, qualitativamente mais radical, processo revolucionário francês. Evidencia-se, também, a total destruição do que restava da ordem feudal, porque a luta de classes nessas formações sociais, assume um nítido caráter de desenvolvimento capitalista, em seu conjunto estrutural. No quadro histórico dessas revoluções, o liberalismo é, objetivamente, a expressão teóricoideológica do momento eminentemente revolucionário de um novo modo de produção e de sua vanguarda - a burguesia (MAZZEO, 1989, p. 109).

A internacionalização dessa civilidade levou o continente americano a iniciar um processo próprio de mudança das práticas desse modelo. Ao se iniciar os movimentos emancipacionistas das colônias frente às metrópoles europeias, as condições históricas e configurações díspares de classes sociais fizeram com que a incipiente e específica burguesia americana também se tornasse revolucionária dentro de uma via denominada por alguns cientistas sociais de "prussiano-colonial", pela forma conciliadora detectada empiricamente.

O termo prussiano advém de Lênin para designar a especificidade do capitalismo alemão e como ainda nos apresenta Mazzeo (1989, p. 109):

Nessa forma social de desenvolvimento temos uma situação em que a fazenda feudal do proprietário de terras se transforma lentamente em uma fazenda burguesa, junker, condenando os camponeses a decênios inteiros da mais dolorosa expropriação. Vemos, assim, que na Alemanha a passagem do feudalismo ao capitalismo se dá de forma lenta, sem rupturas de caráter revolucionário. 
No Brasil, a transição ocorreu dentro dos quesitos das emancipações coloniais e constituições das nações levadas a cabo por arcabouços jurídico-administrativos pautados em monarquias ou repúblicas próprias das engenharias de conformações de classes, resquícios do colonialismo escravista. O fato é que isso fez com que ressignificasse o modelo clássico europeu de capitalismo com suas nuances ideológicas na economia, sociedade e política, pois, limitou os espaços de participações das massas e acomodou os traços coloniais, dando com isso, contornos de uma simbiose das práticas arcaicas coloniais com as modernas práticas sociais, políticas e econômicas. O paternalismo, o fisiologismo e o clientelismo foram instrumentos eficazes para os propósitos da específica burguesia brasileira, de assegurar uma restrita participação social nos destinos da nação, sem riscos de uma revolução mais típica de uma burguesia clássica europeia que garantia espaços mais amplos de participação e assim apresentariam uma sociedade polidamente democrática nos ditames e limites de uma sociedade burguesa instituidora do Estado de direito.

Para corroborar com essas reflexões é salutar a apresentação dessa via específica do caso brasileiro da constituição do capitalismo:

O aspecto "prussiano" aparece, assim, no sentido de caracterização de um processo tardio de acumulação de capital, consagrado na análise leniniana como forma de desenvolvimento burguês, que se enquadra nas grandes tendências gerais de análise da entificação do capitalismo. Pensamos então que, para melhor conceituar o processo brasileiro, a noção de "via prussiano-colonial" é a que mais expressa sua geneticidade, porque respeita a legalidade histórica de sua condição colonial e, ao mesmo tempo, considera a configuração tardia (ou "hipertadia", como quer Chasin) e agrária do processo de acumulação e posterior industrialização do Brasil (MAZZEO, 1989, p.119).

Assim sendo, foi apenas a partir de 1930 que se verificou no Brasil um processo agudo de industrialização com contornos modernos apresentados por uma ínfima parcela da burguesia nacional que tentava colocar na ordem do dia e na agenda do governo e Estado brasileiros à necessária civilidade apregoada nesse momento pelos Estados Unidos da América (EUA). A saída foi, por conta do amálgama das elites consubstanciada na burguesia, garantir uma transição segura da ordem colonial escravocrata, um modo de produção capitalista cuja base e força motriz se fizessem a partir de uma relação de dependência das nações cujas economias já contavam com as aprimoradas máquinas e tecnologias.

Por isso, também é salutar enfatizar a postura dessa burguesia específica brasileira que tem contornos pautados no pragmatismo ao se inspirar nas teorias clássicas do liberalismo, pois por conta de sua trajetória marcada pelo movimento contínuo de uma 
revolução embasada nos ditames de uma conciliação de setores da classe burguesa, foi responsável por uma transição do colonialismo escravocrata de forma segura e de cima para baixo sempre alinhada com as preocupações de limitar espaços de movimentos de cunho social e ilustrado de setores da própria burguesia e da classe trabalhadora. A autocracia foi a solução encontrada, portanto fora dos parâmetros clássicos e originários das burguesias revolucionárias francesa, inglesa e norte-americana.

No Brasil, a recíproca dependência da burguesia nacional e internacional garantiu a industrialização e a modernização dos instrumentos políticos e sociais, mesmo abrindo mão, em alguns momentos, dos princípios norteadores do denominado Estado de direito. É como assevera Florestan Fernandes (1976, p. 291):

O que a parte dependente da periferia "absorve" e, portanto, "repete" com referência aos "casos clássicos", são traços estruturais e dinâmicos essenciais, que caracterizam a existência do que Marx designava como uma economia mercantil, a mais-valia relativa etc. e a emergência de uma economia competitiva diferenciada ou de uma economia monopolista articulada etc. Isso garante uniformidades fundamentais, sem as quais a parte dependente da periferia não seria capitalista e não poderia participar de dinamismos de crescimento ou de desenvolvimento das economias capitalistas centrais. No entanto, a essas uniformidades - que não explicam a expropriação capitalista inerente à dominação imperialista e, portanto, a dependência e o subdesenvolvimento-se superpõem diferenças fundamentais, que emanam do processo pelo qual o desenvolvimento capitalista de periferia se torna dependente, subdesenvolvido e imperializado, articulando no mesmo padrão as economias capitalistas centrais e as economias capitalistas periféricas.

A versão atual no liberalismo, o neoliberalismo, é o norteador dessa engenharia de governança política e econômica, assegurando assim o controle total das esferas políticas e das instituições representativas das classes trabalhadoras, na medida em que age para enfraquecer os sindicatos, partidos e associações representativas da maioria da população trabalhadora desse país.

Enfim, o período onde se constata um crescimento do Produto Interno Bruto (PIB), principalmente pelo processo de urbanização que inchou cidades, transformando-as em metrópoles entre os anos de 1930 e 1970, representa bem o resultado desse amálgama de setores da burguesia (agrária, financeira e industrial) em torno de uma governança que trouxesse segurança para a perpetuação do status quo e imprimissem uma específica formação do capitalismo brasileiro com uma característica de concentração brutal de rendas e uma frágil democracia que deixa de fora os valores clássicos da burguesia, dentre eles os de cidadania. 


\section{AS IMPLICAÇÕES DA “VIA PRUSSIANO-COLONIAL” DO CAPITALISMO NA OCUPAÇÃO DAS TERRAS DO INTERIOR PAULISTA}

A distinção do modelo capitalista brasileiro descrita no item anterior enseja uma análise do processo de ocupação das terras interioranas com seus contornos econômicos e sociais típicos de uma transição lenta da lógica colonial para a lógica capitalista. Na Europa a ruptura com o feudalismo é verificada no processo de renascimento das cidades e do comércio inserido nas condições específicas das relações de produção caracterizadas por mecanismos do modo de produção feudal e do embrião do capitalismo ainda nos moldes da acumulação primitiva, bem como no bojo de conflitos religiosos entre cristãos e árabes. A partir do século XI constatou um fenômeno de concentração de produtos orientais e de pessoas nos entroncamentos de vias e portas de igrejas e mosteiros, acenando para a constituição de burgos e, posteriormente, cidades modernas. As fábricas artesanais impulsionadas pelas guildas e grandes feiras, foram fundamentais para o germe da destruição do feudalismo, pois se verificou outra possibilidade de sobrevivência a partir de moradias em burgos e atividades que possibilitariam uma relativa liberdade em relação ao trabalho servil.

Destarte, por condições e mudança histórica que se depreenderam disso, incluindo as constituições dos estados modernos e a Revolução Industrial, deram contornos próprios às vivências em meio urbano recheado por chaminés de fábricas que revelavam seu grau de tecnologia e modernidade da humanidade. Era a expressão concreta do irromper de uma nova civilidade pela via do capitalismo clássico.

Para o propósito deste artigo será apresentado a especificidade da dinâmica da constituição de cidades no Brasil, que se deu de forma própria por se inserir na denominada "via prussiano-colonial" de desenvolvimento capitalista que suscitou contornos diversos daquele percebidos na Europa.

Verifica-se, portanto, que houve uma subsunção da burguesia brasileira aos polos do capitalismo clássico na perspectiva de consolidação de uma economia que se conforma como subsidiária à grande produção industrial e tecnológica, tendo como consequência direta uma modernização que objetivava uma manutenção dos fundamentos coloniais de sua organização produtiva, motivo de atrasos econômico e social, na medida em que a burguesia agroexportadora articula-se com a burguesia industrial britânica.

A conciliação da burguesia brasileira com o arcaísmo, como um todo, tanto nas relações de produção como nas relações sociais, deu contornos específicos ao processo de povoamento do interior do país, o qual não se deu em entroncamentos de vias e aos redores de igrejas e mosteiros, e sim, em bairros rurais e vilarejos impulsionados pela avidez de 
lucro de uma burguesia agrária exportadora que via no café uma possibilidade de acúmulo de capital cuja condição de relevo e clima os favoreciam para esse intento, principalmente nas regiões sul e sudeste. Uma burguesia que num ritmo lento, porém seguro, buscava sua libertação das amarras do colonialismo escravocrata caracterizadas por mecanismos de produção que atravancavam seu desenvolvimento. A cultura do café impôs uma lógica de exigência de modernização que foi desde o trabalho por meiação, parceria e colonato até assalariamento. Formas modernas de cuidado no manejo do solo e beneficiamento do produto café, também demonstram a tentativas paulatinas de sintonia com métodos mais clássicos do capitalismo.

A consequência disso, foi um modelo de povoamento do interior com apoio do governo da província imperial e depois do governo do estado já na República, levada a cabo por uma política de dependência de investimentos ingleses tanto em capitais financeiros como de maquinários e tecnologias de transportes, tal como vias férreas. É o que nos assevera Pierre Monbeig ao apresentar as mudanças de comportamento e de direção da elite agrária paulista:

A riqueza, os laços com a corte, a política, impeliram os grandes fazendeiros a relações de negócio e a uma vida mundana que os punham em contato com os europeus: com os representantes diplomáticos, os financistas e os pequenos comerciantes do Rio de janeiro, primeiramente; com a própria Europa em seguida. Estavam eles, pois, a par das transformações econômicas e das revoluções políticas da Inglaterra, da França, da Itália e da Alemanha. Era normal que procurassem inspirar-se nelas ou a delas tirar partido (MONBEIG, 1984, p. 96).

Para a engenharia de produção do café, precisava também otimizar e tornar eficaz o modelo da produção quanto à utilização de recursos humanos. Para isso, buscaram a solução a partir de atração de mão de obra de imigrantes europeus, principalmente de espanhóis, portugueses, alemães e japoneses que com recursos advindos do governo do Estado de São Paulo e das associações dos próprios fazendeiros, inundaram as terras do interior paulista nos primeiros bairros rurais que margeavam a linha férrea construída para logística do comércio principalmente voltado para o mercado externo. Portanto, diferente de burgos, como na Europa, no interior paulista as aglomerações de pessoas se darão inicialmente em bairros rurais de hábitos e costumes ainda bem distantes da modernidade das vivências das cidades europeias.

$\mathrm{Na}$ esteira desses acontecimentos, primeiramente os agrupamentos humanos se deram em bairros rurais já verificados no território do Estado de São Paulo desde fins do século XVIII e a partir de fins do século XIX com a chegada de massas de imigrantes 
europeus, os mesmos terão outro componente sociocultural dando novas configurações na paisagem rural paulista.

Percebe-se, com isso, que além dos motivos de impulsionamento já demonstrados acima, temos também que enfatizar a política agrária implementada pelo Império brasileiro a partir de 1850 com a denominada Lei de Terras, facilitando sobremaneira a posse de terras no território paulista, principalmente na frouxidão no cumprimento da mesma no que diz respeito à posse de terras devolutas. O apossamento em grande parte do território paulista se deu de forma fraudulenta e violenta com extermínio de índios e facilitação de entradas de companhias estrangeiras que comercializariam as terras a partir da avidez em também produzir o produto da época de maior lucratividade, o café.

Como decorrência desses fatores, houve um desmantelamento de quase todas as tribos do Estado de São Paulo. O caso emblemático se remete aos Caingangues, 0 último grupo aborígene deste território. Em nenhum lugar do país é mais intensa, em fins do século XIX e início do século XX, a penetração para a ocupação, comércio e organização da produção nas denominadas terras devolutas. Com isso, a intensidade do genocídio em relação a esses povos se dá proporcionalmente pelas dimensões e velocidade do movimento específico de ocupação.

Os bairros rurais paulistas surgiram no bojo do desenvolvimento pela via do capitalismo "prussiano-colonial" já apresentada anteriormente, pois não foram impulsionados pelo comércio de mercadorias industrializadas e muito menos por indústrias de grandes dimensões e sim através de empreendimento de uma incipiente burguesia agrária ainda em processo de mudança no que diz respeito em aplicar as técnicas para o acúmulo de capitais praticados pelos capitalistas da via clássica verificadas na Europa.

Vale para o propósito desse item, denominar bairro rural e caracterizá-lo para embasar a peculiaridade da formação de aglomerações humanas no território paulista:

\footnotetext{
Estabelecia-se uma rede estreita de relações entre os roceiros pertencentes ao mesmo grupo de vizinhança, que adquiriam consciência da unidade e do funcionamento deste. Configuração social intermediária entre família, de um lado, e de outro lado o arraial, ou a vila, ou a cidadezinha, o bairro apresentava as formas mais elementares de sociabilidade da vida rústica, que se alargavam em diferentes graus a partir dele, na seguinte escala: a) relações familiares; b) relações de vizinhança; c) relações de bairros entre si; d) relações com a região; e) relações com o exterior (isto é, com tudo que ultrapassa a região). Tal gradação indica que os bairros, constituindo embora unidades funcionais relativamente autônomas, eram sempre tributários de um povoado ou de uma cidadezinha. (QUEIROZ, 1973, p. 4)
}

Esse desenho de constituição dos povoados no interior de São Paulo denota 
emblematicamente a rusticidade de uma burguesia que atravancará a evolução do capitalismo e a modernização das cidades. Isso decorrerá do atraso do surgimento das camadas médias da burguesia o que comprova a tardia inserção de práticas e valores clássicos de relações sociais e de produção. Somou-se a isso, a demora da penetração de tecnologias de produção no campo e a decantada civilidade que caracterizou a promessa das revoluções burguesas que somente se iniciará com a opção de dependência do capitalismo externo levado a cabo pela substituição das importações.

O primeiro ato concreto que demonstrou um dos componentes da modernidade em territórios paulista foi a locomotiva que desde 1867 transportava o progresso e trazia um imaginário caracterizado por uma crença alvissareira de esparramar para terras inóspitas do Estado de São Paulo as práticas capitalistas que trariam segurança em plena transição do período colonial e constituição de uma nação sob governança do Império e depois de uma República aos moldes de uma burguesia agrária.

O adensamento demográfico, portanto, ocorreu com a parceria ferrovia e café, tendo como marca indelével o surgimento de bairros rurais e cidades, delineando também regiões que trariam identidades geográficas aos seus moradores por estarem, por exemplo, na AltaPaulista, Vale, Sorocabana, Mogiana, Noroeste ou na Araraquarense.

Aconjuntura internacional que demonstrava alguns problemas cíclicos do capitalismo fez com que o Estado de São Paulo se obrigasse a inverter a importação de produtos de uso doméstico e partir para um processo próprio de produção para o consumo interno:

Acontecimentos internacionais de peso regeram parte desse movimento crescente, exigindo investimentos alternativos e a aposta decisiva na atividade industrial. As duas guerras mundiais (1914-1918 e 1939-1945), entremeadas pela quebra da bolsa de Nova York (1929), demandaram a busca de soluções imediatas para o suprimento do mercado interno e para a diversificação agrícola, estímulos que favoreceram a gradual substituição dos produtos manufaturados e insumos que favoreceram pelo similar nacional. Num primeiro momento, antes da Crise de 1929, indústrias de tecidos, papéis, alimentos e implementos agrícolas conheceram desempenho estimulante para apostas mais arrojadas no setor. A partir de 1930, as políticas nacionalistas implementadas permitiram aportes necessários para investimentos na área. (MARTINS, 2008, p. 54)

Enfim, o contexto descrito acima ditará o desenho de paisagem urbana no interior do Estado de São Paulo, posto em prática pelos governos municipais com inspirações modernas baseadas nas cidades do Rio de Janeiro e São Paulo. A homogeneidade da paisagem urbana parte de uma elite que de costas para as singularidades das regiões díspares do Estado de São Paulo, mimetizam essas capitais a fim de também garantirem as otimizações e racionalidades típicas das cidades pós Revolução Industrial. 
As legislações concernentes ao meio urbano tais como "Código de Postura" e "Ocupação e Uso do Solo", possuem em seu bojo a tentativa de uma civilidade que confronta os hábitos locais e exclui milhares de pessoas a um uso democrático dos espaços públicos que aos poucos dão conformidades às elites locais.

\section{O TARDIO MIMETISMO DAS DIMENSÕES DA SOCIABILIDADE BURGUESA NO INTERIOR PAULISTA}

Em decorrência do que foi exposto até aqui, verifica-se um atraso em relação às formações dos espaços no interior paulista de onde veiculam formas de convívio a fim de garantir redes de relações nos diversos âmbitos que envolvem o cotidiano de pessoas verificadas na Europa do capitalismo clássico. Disso depreende um estudo sobre as dimensões de sociabilidade nessas circunstâncias específicas que deram contornos a formação de valores, hábitos e costumes da população que ocupou essa região do Brasil na busca de um mimetismo que asseguraria a ideia de sintonização com o progresso e civilidade.

É salutar conceituar redes e apresentar como se deram as circunstâncias proporcionadoras de civilidade garantidora de uma nova identidade saindo da lógica da vida privada para a inserção da convivialidade da vida pública.

É pertinente para esse artigo mencionar o conceito de redes através de Baechler (1995, p.77):

[...] os laços, mais ou menos sólidos e exclusivos, que cada ator social estabelece com outros atores, os quais estão também em relação com outros atores, a assim por diante. A priori, podemos pressentir que a amplitude, a exclusividade e a densidade da trama das redes variará inteiramente conforme se tenha em consideração as redes de parentesco, de vizinhança, de classe ... Uma segunda categoria poderia ser definida por redes de algum modo deliberadas, no sentido de que são definidos espaços sociais, onde se encontram, por opção, atores sociais que têm prazer e interesse em ser sociáveis uns com os outros.

A intencionalidade de se criar padrões e regras de convivência visando cimentar uma sociedade, fez com que homens e mulheres evocassem uma modernidade a partir do século XVI, onde pensaram na ótica de uma civilidade e dos cuidados e vigília para seu uso. Para isso produziram literaturas da civilidade caracterizadas por manuais orientadores de normas e regras de condutas. Entre os séculos XVI e XIX, a população europeia abandonava as preocupações de formas de vivência privada para se inserir numa outra preocupação, agora embasada nos comportamentos da coletividade, portanto pública. 
Período auspicioso para o controle de corpos e mímicas que ludicamente demonstravam a evolução humana a partir de uma civilidade que garantia uma identidade de grupo em pleno período de transformações políticas, sociais e econômicas.

Para esse raciocínio é importante destacar a assertiva de Jacques Revel (1991, p.169):

[...] Com efeito, o século XVI é o de um intenso esforço de codificação e controle dos comportamentos. Submete-se às normas da civilidade, isto é, às exigências do comércio social. Existe uma linguagem dos corpos sim, porém destina-se aos outros, que devem poder captá-la. Ela projeta o indivíduo para fora de si mesmo e o expõe ao elogio ou à sansão do grupo. As regras da civilidade que se impõem então podem ser compreendida como uma manobra para limitar ou até mesmo negar a vida privada.

Essa concepção de civilidade, principalmente verificada nos vocábulos ingleses e franceses denotam uma perspectiva de demonstrar um padrão calcado no ápice da evolução da humanidade, que servirá como uma régua para medir outras sociedades dentro e fora do continente europeu. A ideia de progresso permeou as invenções de instituições políticas, sociais e educacionais, para se consolidarem vivências pautadas em valores de uma vida urbana e industrial. Lançaram mão de escolas, clubes, associações, partidos, sindicatos, etc., a fim de veicularem os valores e controlar atitudes na perspectiva de uma identidade de grupo. Inventam-se tradições e essas são dimensionadas a partir de necessidades de consolidar as instituições políticas das nações recém-formadas, agora pautadas nos quesitos revolucionários da classe burguesa.

No que diz respeito ao caso específico do território paulista a partir do século XIX, percebe-se a existência dos incipientes núcleos urbanos povoados por pessoas de várias nacionalidades e destarte de várias regiões do Brasil, e, assim como já estava em andamento nas capitas do Rio de Janeiro e São Paulo, buscaram vasos comunicantes com uma civilidade espelhada nessas cidades verificadas na França e Inglaterra e criaram espaços de sociabilidade com contornos próprios para a distinção de grupos e a veiculação de valores que ora era de crenças religiosas, ora de nacionalidades ou até mesmo de uma incipiente burguesia que já procurava sua distinção de classe.

Os clubes sociais, associações, clubes de serviço, museus, igrejas e escolas e doravante rádio e televisão, também se inscreveram na ordem social para que, aqui, se sentissem modernos e dentro dos parâmetros de uma convivialidade que lhes davam segurança identitária dentro de uma diversa paisagem colorida pelo povoamento de grupos oriundos de diversas regiões estrangeiras como da Itália, Portugal, Espanha, Alemanha, 
Japão e de regiões brasileiras, tais como Nordeste e Norte.

Embora a grande maioria das cidades paulistas não contasse com esses espaços, a existência dos mesmos para a dimensão de sociabilidade inseridos no contexto de um desenvolvimento tardio do capitalismo no território paulista, em alguns municípios onde se verificou a entrada da incipiente indústria paulista, tais como São Paulo, Campinas, Itu, Tatuí, Sorocaba, Piracicaba, Jundiaí, Santa Bárbara, Rio Claro e São Luiz do Paraitinga, ou de alguns outros nascidos às margens de vias férreas, demonstra a tentativa das elites em homogeneizar narrativas no campo da história criadoras de epopeia e do mito do pioneirismo civilizador das terras inóspitas do território paulista e com isso buscavam suas distinções e status.

As presenças de práticas no campo da política e no campo social, pautadas no fisiologismo, clientelismo e coronelismo, corroboram para a justificativa de que aqui, principalmente no interior do Estado de São Paulo, esse viés de capitalismo prussianocolonial, deixou marcas indeléveis que fragilizou a renda e o acesso à cultura e educação, escancarando os meios urbanos de cidade que se constituíram sem as preocupações de inclusão das pessoas numa existência de qualidade nos seus espaços públicos.

\section{CONSIDERAÇÕES FINAIS}

Para a compreensão do contexto proporcionador de um processo específico de povoamento do território paulista, principalmente no seu interior, que trouxe consequências econômicas, sociais e políticas para milhares de pessoas que foram expropriadas, violentadas e praticamente extintas, tais como os Caingangues, Oti-Xavantes, diversos africanos retirados à força e açoitados nas condições de escravos em diversas fazendas produtivas agroexportadoras e os imigrantes atraídos principalmente dos campos e cidades dos países como Itália, Espanha, Alemanha, Portugal e Japão, neste caso, reflexo do desemprego levado a cabo pelo capitalismo industrial que transformava o campo em unidades produtivas modernas na Europa, enseja também uma inteligibilidade das condições próprias do desenvolvimento das forças produtivas verificadas empiricamente nesse espaço.

As diversas pesquisas concernentes aos espaços urbanos de cidades dessa região, precisam lançar mão de metodologias que contemplem a interdisciplinaridade das ciências sociais a fim de chegar a resultados que não sejam superficiais e enviesados. Portanto, a Antropologia, Geografia, História, Psicologia e Sociologia ao elegerem essa temática precisam inserir o viés dos estudos sobre as vias do capitalismo a fim de sintonizar os aspectos estéticos, sociais, arquitetônicos e de espaços de sociabilidade. 
Nesse sentido, o artigo procurou apresentar a necessária interface entre a estrutura e superestrutura para a compreensão das tramas sociais em torno das preocupações de homens e mulheres nos usos da civilidade a partir de instituições norteadoras de distinções e solidificações de identidades no processo de povoamento do interior do Estado de São Paulo, além das significações dadas às ocupações dentro do escopo do pioneirismo responsável por irromper o atraso e assim instaurar a civilidade apregoada nos moldes das civilizações clássicas ocidentais.

Enfim, vale ressaltar a importância do respeito aos rigores das metodologias e conceitos das ciências sociais para a tessitura da inteligibilidade sobre os componentes constitutivos da formação das elites paulistas no bojo da transição do colonialismo escravocrata para o capitalismo dependente, permeada por encontros de povos de várias regiões do Brasil e de imigrantes, os quais ensejaram instituições que denotaram as negociações de identidades e distinções de classe.

\section{REFERÊNCIAS}

BAECHLER, Jean. Grupos e Sociabilidade. In: BOUDON, Raymond et al - Tratado de Sociologia. Rio de Janeiro: Jorge Zahar ed., 1995.

ELIAS, Norbert. O processo civilizador. Rio de Janeiro: Jorge Zahar, 1994. v.1

FERNANDES, Florestan. A revolução burguesa no Brasil. Ensaio de interpretação sociológica. Rio de Janeiro: Zahar Editores, 1976.

LANDIN, Paula da Cruz. Desenho de paisagem urbana: as cidades do interior paulista. São Paulo: Editora Unesp, 2004.

MARTINS, Ana Luiza. Interior paulista: comércio, indústria e bancos. In: SETUBAL, Maria Alice (Coord). Terra Paulista: trajetórias contemporâneas. São Paulo: CENPEC, Imprensa Oficial do Estado de São Paulo, 2008.

MAZZEO, Antonio Carlos. Estado e Burguesia no Brasil. Origem da autocracia burguesa. Belo Horizonte: Oficina de Livros, 1989.

MONBEIG. Pierre. Pioneiros e fazendeiros de São Paulo. São Paulo: Editora Hucitec: Editora Polis Ltda., 1984.

QUEIROZ, Maria Isaura Pereira. Bairros Rurais Paulistas. Dinâmica das relações bairro rural - cidade. São Paulo: Livraria Duas Cidades, 1973.

REVEL, Jacques. Os usos da civilidade. In: ARIES, P \& DUBY, G. História da vida privada. n 3. São Paulo: Cia das Letras, 1991. 